\title{
NARRATIVES OF RESILIENCE AMONG \\ LEARNERS IN A RURAL PRIMARY SCHOOL IN SWAZILAND
}

\author{
Ncamsile Daphne Motsa \\ University of KwaZulu-Natal \\ ncamsiledaphne@gmail.com \\ Pholoho Justice Morojele \\ University of KwaZulu-Natal \\ Morojele@ukzn.ac.za
}

\section{ABSTRACT}

Drawing from the concepts of social constructionism, the article provides insights on how six purposively sampled Grade 6 vulnerable children, aged between 11-15, from povertystricken families, child-headed households and those allegedly orphaned by AIDS, resiliently navigated their schooling spaces and places in one rural, primary school in Swaziland. The article uses qualitative data from semi-structured individual and focus group interviews and a participatory research method, photovoice, to foreground narrative accounts of the vulnerable children's creative coping mechanisms aimed at overcoming the unfavourable circumstances of their schooling experiences. Despite facing some home- and school-based challenges, the vulnerable children were found to display deep-rooted resilience, with or without social support and aspiration for educational attainment, seen as a viable alternative for a better future. Creative coping mechanisms that vulnerable children adopted included calculated rebellion against abusive teachers and consignment to solitude or isolation when feeling overwhelmed by unpleasant experiences. It is recommended that support strategies should involve affirming vulnerable children's voice and resilience, drawing on how these children already creatively navigate their challenges.

Keywords: children; vulnerable; resilience; experiences; school; rural; Swaziland

\section{INTRODUCTION}

This article explores narratives of resilience among rural primary school learners against the backdrop of major structural economic and social inequalities in Swaziland,

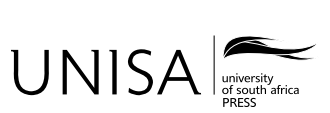

Education as Change

Volume 21 | Number 1 | 2017 | pp. 155-173

www.educationaschange.co.za

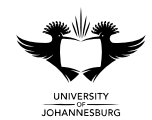

DOI: http://dx.doi.org/10.17159/1947-9417/2017/1081 Print ISSN 1682-3206 | Online 1947-9417

(C) 2017. The Author(s) 
which all converge in complex, but complementary ways to render and increase the number of vulnerable learners in this context. Swaziland has over the years failed to alleviate poverty and uphold the first Millennium Development Goal (MDG). In 2015, the country stood at 0.541 in the Human Development Index (HDI), placing it in the low human development category at position 148 out of 188 countries (UNDP 2016). In Swaziland, poverty has been caused by a number of factors, such as the low employment rate, which in 2013 was at 30 per cent of the total population, with 52 per cent of the people in the rural areas not employed compared to 23.6 per cent in the urban areas (Swaziland 2012). Swaziland's effort for economic growth has over the years been undermined by misuse of public funds and resources (UNDP 2012), which has led to a wide discrepancy between the poor and rich, with the economy skewed towards the rich people (Kingdom of Swaziland 2010). The misappropriation, mismanagement and misguided priorities of public funds has carried on unabated in the country because Swaziland does not have an ombudsman to deal with issues of corruption and financial accountability (Khumalo 2013).

Swaziland is thus practically incapable of sustaining itself economically and heavily relies on the customs revenue from the Southern African Customs Union (SACU), which supplies about 60 per cent of the country's overall budget (Braithwaite, Djimba and Pickmans 2013). The funds from SACU are also not consistent. For instance, in the 2010/2011 year, the customs revenue was reduced from R5.1 billion in 2009/2010 to R1.9 billion, which led to a huge national budget deficit that was cut by 14 per cent in 2010/2011 and 20 per cent in 2011/2012 (Khumalo 2013). Even after SACU slightly increased the proceeds for the country in 2012/2013, the state is still a long way from being capable of paying for its expenditures (Swaziland 2012). Access to education is still unsatisfactory and most inclusive educational policies in Swaziland only exist on paper and their actual implementation is very poor (Khumalo 2013). For example, the government introduced Free Primary Education (FPE) in 2010, but because of scarcity of funds, it is still unable to make payments in time and the money paid to schools is not enough to cater for the learners' education (Sukati 2013). Hence, principals demand additional fees dubbed "top up fees" from parents or guardians and children who cannot pay are punished or even expelled from school (Nordveit 2010). Deeply-rooted dynamics of patriarchy and the undemocratic nature of the Swazi society do underlie many social challenges of inclusivity and support for vulnerable children.

These structural socio-economic problems in the country coupled with the effects of HIV and AIDS (with $26.1 \%$ of people between the ages 15-49 being HIV positive [Swaziland 2012]) have made life almost unbearable, especially for the rural population where 84 per cent of Swaziland's children live (UNICEF 2009). The disastrous effects of HIV and AIDS are, indeed, enhanced in a country where there is already a high level of socio-economic inequalities. Consequently, the number of children who have been rendered vulnerable has drastically increased. In 2016 alone, schools in Swaziland had about 150000 vulnerable children (Simelane 2016) in a population of about 1.1 million 
people (Braithwaite, Djimba and Pickmans 2013). The Swaziland Ministry of Education and Training (2011) considers vulnerable children to be: orphans, children living in child-headed households, and those from poor social and economic backgrounds mostly due to the effects of the HIV and AIDS pandemic. These children are locally referred to as bantfwana bendlunkhulu (those cared for by the whole community) and their school fees are paid by the state. Although the reasons that render children vulnerable may differ, these children share one thing - and that is vulnerability and poverty (Nordtveit 2010).

Historically it took a village to bring up an African child, but with the status quo caused by the unprecedented challenges of poverty, unemployment and AIDS, the means of survival are hard to get by, forcing most Swazi communities and families to concentrate on the livelihood of their own families, which Jans (2004) defines as individualisation. The lack of responsibility and willingness for extended family members and communities to help children in dire circumstances is an indication of the disintegration of the African family, and indeed a drift away from the spirit of African communalism (Garutsa 2012) - commonly known as Ubuntu or Buntfu in SiSwati. Furthermore, the deaths of a number of family members due to AIDS has rendered most affluent families unable to adequately cater for the vulnerable children's basic needs (Nordtveit 2010), including educational prerequisites.

Societal stereotypes that permeate school contexts affect the educational experiences and academic attainment of vulnerable children (Lekule 2014). In the communities, vulnerable children, especially orphans, are discriminated against and socially excluded because they are associated with HIV as their parents' death are attributed to HIV and AIDS (Nyabanyaba 2009). Local community members believe that vulnerable children are spoiled (Lekule 2014) and they are further socially excluded because of the perceived preferential treatment they receive from Western organisations (Voyk 2011). Vulnerable children are also easy targets for violent acts like bullying and ostracising by teachers because of their failure to meet school requirements such as doing homework and coming to school on time (Nordtveit 2010).

In the rural areas of Swaziland particularly, most vulnerable children have dropped out of school due to the aforementioned problems (Nordtveit 2010) and the state's inability to abide by its promise of providing education that is completely free (Braithwaite et al. 2013). Under such conditions child and human development in general is certain to deteriorate further. Without education, which is regarded as the foundation of social and economic development (Sutton, Smith, Dearden and Middleton 2007), the circle of poverty and vulnerability for vulnerable children is set to be perpetuated and furthermore to increase the strain on the weakening economy of the country. Swaziland's currency is a legal tender regarded as equivalent to the South African rand, even though the economic realities of Swaziland make this equivalence unfeasible. This currency agreement with South Africa has had a downside, causing Swaziland to be considered as a lower-middle income country, which is thus not eligible to benefit from certain 
donors that could support desperately needy children who require financial assistance to survive (Naysmith, Whiteside and Whalley 2008). Certainly an independent currency would show the world how poor this country is and therefore enable commensurate aid support systems to alleviate the plight of the vulnerable Swazi children.

\section{THE GEOGRAPHICAL AND SOCIO-ECONOMIC CONTEXT OF THE STUDY}

The Lubombo region, (where the study was undertaken) is one of the four geographically diverse regions in Swaziland. Wabo Primary school (a pseudonym) is located in the rural Lubombo region, which is the hottest and driest region, located on the far-east side of the country, bordered by Mozambique. Lubombo is largely rural, with 76 per cent of its schools being in the rural areas (Kingdom of Swaziland 2013). It is also the region most affected by poverty, drought, HIV and AIDS (UNICEF 2009), making it the region with the highest percentage of vulnerable children in the country, which in 2011 stood at 37 per cent (Braithwaite et al. 2013). Unfortunately, it is also the most deprived in terms of education (UNICEF 2009) with a large number of children engaged in child labour (Nordtveit 2010). Retrenchments in the local sugar companies have complicated things for the local people who have been forced into employment for food and some households generate cash through the sale of home brewed beer as their only source of income.

\section{RESILIENCE, AGENCY AND VULNERABLE CHILDREN}

Resilience is defined as an ability to overcome hardships in life (Malindi 2014; Ungar 2005). Hence, a resilient child is one who strives for a better life and remains effective and proficient (Glover 2009) even in the most difficult circumstances (Ungar 2005). Studies (e.g. Malindi and Theron 2010; Malindi 2014; Noltemeyer and Bush 2013; Ungar 2008) suggest that childhood resilience is reliant on both the child's individual characteristics and the support offered by his or her community in fostering wellbeing. Resilient qualities in children include qualities such as humour, boldness and agency (Malindi and Theron 2010). For the vulnerable children resilience, therefore, involves the ability to exercise the human capital of agency to navigate and negotiate their way towards educational success supported by their social context (Malindi 2014). In essence, vulnerable children's capability to be resilient relies on their assertive personality, society, the support structures around them (Ungar 2008) and how the environment continuously nurtures their insistent disposition (Theron 2012).

Resilience is an important skill needed by all vulnerable children to cope with the harsh reality of their schooling experiences and life in general. Pooley and Cohen (2010) posit that vulnerable children's resilient abilities can be inculcated by affirming their voice, and helping them have a sense of belonging and self-efficacy with a strong 
understanding of the strengths they possess to engage with their trying situations. A critical point of emphasis is that, whatever could be imagined or done about resilience would first need to draw on how vulnerable children's propensities and attributes to be naturally resilient, and the support they receive, help them to overcome challenges in their lives.

Hence, the objective of this paper is to highlight how vulnerable children creatively exercised their resilient agency as a mechanism to navigate their complex schooling lives and how their environment developed and nurtured their resilience in a positive or destructive way. Although this article tends to understand children's resilience in individualistic terms, the aim was to foreground the creative and innovative individualistic ways through which children navigate the structural socio-economic inequalities, as a vantage point of entry into the personal lives of children and their creative potential. The article is premised on the assumption that understanding children's narratives of personal resiliencies, in this context, would shed critical light on how to harness the children's creative capacities in order to improve broader issues of social transformation and inclusivity in education. As illustrated, clearly the central problem lies with the exclusion of these vulnerable children from participating fully in school and society. Hence the article makes recommendations concerning how educational reformists could capitalise on children's creative personal resilience to devise strategies aimed at improving vulnerable children's educational attainment and the quality of their schooling experiences.

\section{SOCIAL CONSTRUCTIONISM: A THEORETICAL PERSPECTIVE}

This study draws on notions surrounding social constructionism. Social constructionism suggests that, all that we take to be truthful (including resilience) develops from and is consistently imbedded in our society's traditions and values (Gergen 2009). Resilience is therefore a social construct that is contextually and culturally located, making individual communities' cultures and social relationships responsible for how people perceive, construct, and approach challenges in life (Ungar 2008). It is both an individual capacity used to navigate to wellbeing and also has to do with the community's resilience formation (Ungar, Russell and Connelly 2014) and how able the individual's family, community and culture are to provide resources for resilience in culturally meaningful ways (Ungar 2005).

Social constructionism further places emphasis on discourse and social relations as bases on which learners' resilient abilities are predicated (Gergen 2009). Gee (2011) sees discourse as a socially accepted association among ways of thinking, feeling, believing, valuing, and acting that can be used to identify oneself as a member of a socially meaningful group. A resilient community is therefore one that provides its people with resources for the formation of resilience (Noltemeyer and Bush 2013). In 
essence, vulnerable children's resilience is subject to both their individual personalities that seek to help them rise above their poverty and vulnerability, and their support structures, in the form of the community, culture and their social relationships with peers, family, and the school. Discursively constituted social relations are therefore a key phenomenon informing learners' resilient abilities.

In this regard, this article shows how the learners' resilient abilities are intricately entangled with the dominant social discourses of resilience in their communities. How the vulnerable children thrive and cope with their adversity goes beyond their individual capability to do so and extends to how they perceive this capability, which is informed, supported and rooted in their social relationships and the dominant discourses of resilience in their society (Gergen 2009). The paper further highlights how the vulnerable children creatively used their hidden resilient agency as a mechanism to navigate their complex schooling lives, and how historically constituted repertoires of the vulnerable children's relationships with their community and school spaces informed their subjective resilient abilities in the school context.

The theoretical perspective enabled the article to illuminate the broader societal resilience or structural deficiencies in dealing with the hardships that the vulnerable children's individual communities and the school presented. Through the participants' stories, we understood that, the poverty, structural socio-economic inequalities, and the effects of HIV and AIDS that the community has experienced for the past two decades have disintegrated families and communities and that in most instances the vulnerable children coped through their hidden resilience, which, albeit, proved insufficient to foster educational excellence. Our analyses and recommendations thus concern how vulnerable children's individualist resilience capacities could be harnessed to achieve broader imperatives of social transformation and their meaningful participation and inclusion in education. We further learnt how the environment can provide a basis for the reinforcement of delinquent behaviour, as the vulnerable children's only alternative pathway to resilience (Ungar 2005). Indeed, the learners' narratives on resilience proved to be an embodied reflection of the dynamics of social relationships in their family, school and community contexts.

\section{CONDUCTING RESEARCH WITH VULNERABLE CHILDREN}

\section{Research Methodology, Design and Methods}

Drawing from a case study of one school in the rural Lubombo region of Swaziland, the study used a qualitative narrative inquiry approach as its methodological design. The participants consisted of six Grade 6 vulnerable children (aged between 11-15 years), three males and three females, who were purposively sampled. Two were orphans, two were from child-headed households and two were from poverty-stricken families (1 
male and 1 female for each pair). Individual and focus group semi-structured interviews were used as a platform to solicit vulnerable children's stories about how they navigated their community and school spaces. A children's participatory photovoice technique was also employed. For photovoice, each participant was given a disposable camera with 27 frames. The participants were trained to use the cameras, and were then urged to capture their chosen salient spaces and places that held meaning for their real-life schooling experiences either in an affirmative or undesirable way (Joubert 2012) for a period of four days, after which the frames were developed. The photo imagery was then used as a basis for both individual and focus group interviews as ingress into the views, perspectives, and lived experiences of the study participants (Mitchell, Moletsane, Stuart, Buthelezi and de Lange 2005), and further enabled the active involvement of the participants as they took the images and helped in their analysis. This situated the participant children as active agentic actors not only in shaping the dynamics of their lives, but also in shaping the knowledge they would like this study to produce in respect of their real-life schooling experiences. With permission of the participants, the use of a tape recorder helped to capture accurately what each participant said and to make up for data not recorded in notes. All interviews were conducted in SiSwati to allow participants to talk and express themselves without any linguistic restrictions (Mcmillan and Schumacher 2010) as the vulnerable children narrated deep details of how they navigated and coped with their complex schooling spaces and places.

The aim of this study was to place vulnerable children in the centre of the study to make them not only active participants who can contribute to a drive for change but co-researchers who have a credible voice in matters affecting their lives (Gallacher and Gallagher 2008). Thus the choice of photovoice with its potential to make participants collaborate in research and not just become passive contributors. Photovoice was also chosen for its ability to act as a voice for the society's most vulnerable population in expressing not only their socio-economic challenges (Wang 1999) but also issues of concern to them and by extension to their communities. Considering that the vulnerable children's narratives and voices were socially and historically situated, they thus reflected the socio-economic status and dynamics of their individual societies (Gergen 2009).

\section{Data Analysis Procedures}

Data was translated from SiSwati into English for easy analysis. An inductive process of analysis was followed to derive patterns and themes from the data (Braun and Clarke 2006). We listened to the recorded data while reading the transcriptions for accuracy in interpretation (Di Cicco-Bloom and Crabtree 2006). Data was then organised, linking pseudonyms with informants. This was followed by reading line by line and listening to the recordings again to familiarise ourselves with the data and to identify sub-emerging themes related to vulnerable children's schooling experiences. This was guided by the 
research questions of the study. The tone of voice of the participants was also noted especially in comprehending their emotions. The emergent themes were then coded and the pictures selected and contextualised with assistance from the participants. The themes that emerged from all the data (photovoice, individual and focus group interviews) were then analysed and discussed in view of the theoretical framework of the study.

\section{Ethical Considerations}

Consent for the research was sought from the director of schools in Swaziland, the school principal and from parents and caregivers of the participants. Considering that some vulnerable children had neither parents nor guardians, letters of consent for such participants were written to the community caregiver (umgcugcuteli). Ethical clearance was then obtained from the University of KwaZulu-Natal research office. As the study views children as competent human beings who can decide on issues that concern their lives, their consent was also sought. In this paper, pseudonyms which the participants chose themselves are used to protect their identities.

\section{THE FINDINGS}

\section{Resilience, Hope and Optimism}

The findings revealed deep-rooted resilience, agency and perseverance displayed by the vulnerable children in their daily struggles to negotiate and traverse even the worst conditions of their educational life. A sense of hope and optimism, a deeply-held belief that education is the only viable alternative that could alleviate their plight and life challenges in the future (Sutton et al. 2007) seemed to have been a catalyst behind the vulnerable children's display of agency towards resilience. The narratives below illustrate the vulnerable children's positivity, faith and resilient behaviours, based on a strongly held conviction that once educational goals are achieved, all their life difficulties will be a thing of the past:

I am one person who forgives easily, so even with the bad treatment here I am never bitter. Each time I come to school I do so because I know that once I am done with my education, all this will be history. I will only have a faint memory of all the challenges I am facing now.

(Sfiso*, boy aged 12; focus group interview)

I am a hard worker. Even though I have so much work to do at home, I still try to give myself time with my books. If there has been no candle the previous night, I make sure that I wake up as early as 4.30 am so that I get to school early and write my schoolwork before the teachers arrive. It is not an easy thing but I understand that, I have no one to help me therefore I have to work harder than other learners do. Otherwise, I will die poor.

(Precious*, girl aged 13; focus group interview) 
Precious also provided the picture below to illustrate her strength of character as she gets ready for school in the morning.

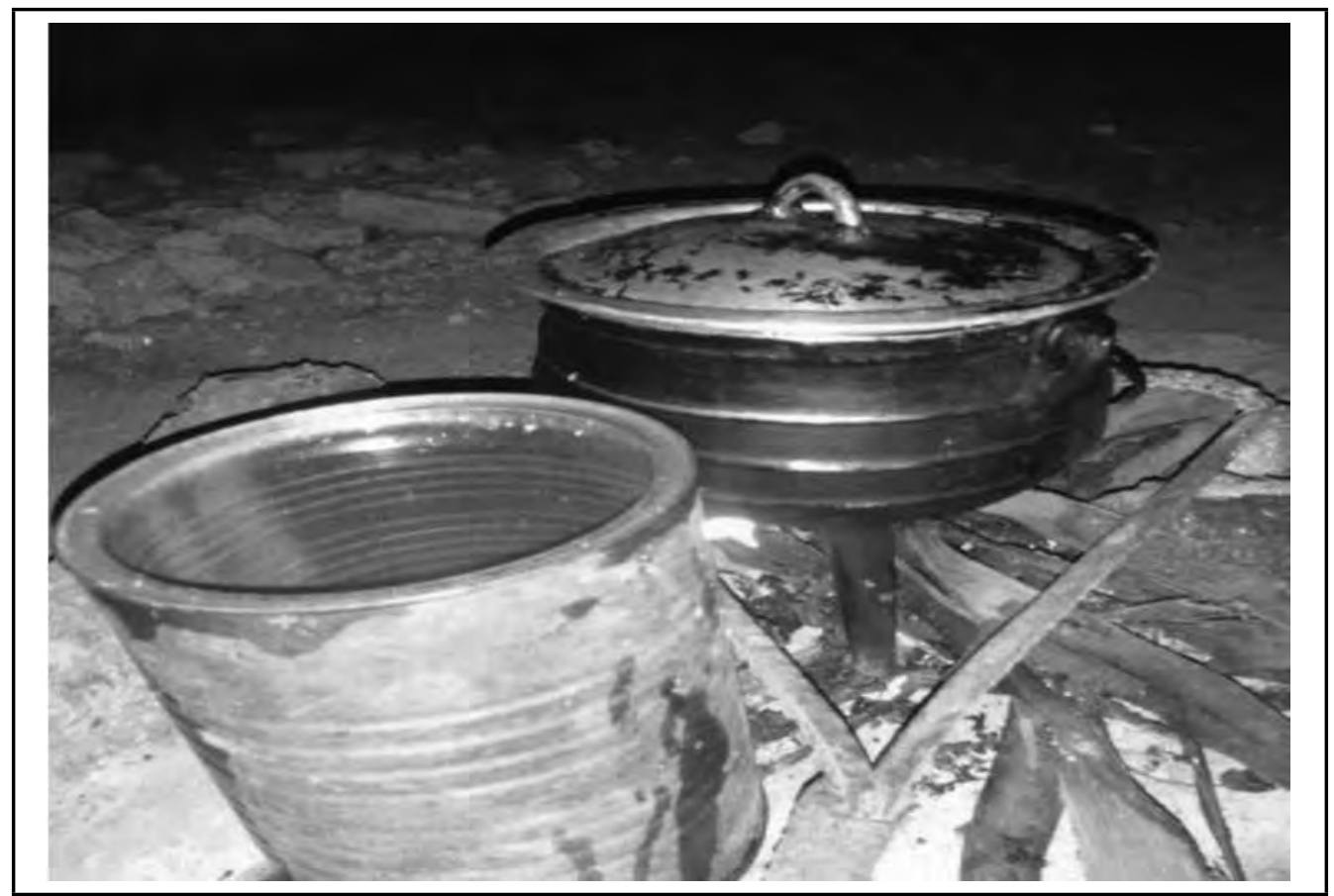

Figure 1: Picture 1

Interviewer: Precious please tell me what is happening in this picture?

Precious: Remember auntie, I told you that I wake up at $4.30 \mathrm{am}$. I have to heat water and cook my breakfast in the open, even on rainy days. Other children have domestic workers to help them and their homes have electricity, but not for us, we do not have electricity or anyone to help. Therefore, I have to do all this without any help, and then rush to school to ensure that by 7.40 am, all assignments are written.

(Precious*, girl aged 13; individual interview)

The findings illustrate that even though the vulnerable children's home lived experiences were challenging, they were able to utilise their human capital agency to deal competently with threats to their education (Ungar 2008) and by extension their visualised future lives. They relentlessly continued with their education because they were motivated by the assurance of a better future, seeing that education and educational achievement is the key component for personal and social development (Sutton et al. 2007). Children's assertive personalities seemed to have played a significant role in nurturing their hidden resilience (Ungar 2007), thereby affirming children as creative, active social agents and the unique individuality of every child (Van Blerk 2005). Each vulnerable child in the 
study seemed to have had a unique resilient personality upon which to draw to navigate daily struggles in order to cope with their life challenges. Such was the only recourse these children had to facilitate educational success (Malindi and Theron 2010) in the absence of structural and institutional support mechanisms available to alleviate their plight.

Precious's narration further illustrates a strong sense of determination. Waking up at 4:30 am in the dark and making a fire in the open on cold days so that she could have hot water and breakfast before rushing to school to write assignments before school resumes is one such example. This shows the strong willpower of a child who has risen above her circumstances and mastered how to navigate her home situation, which was different from other learners not affected by vulnerability. A resilient mindset, hope, and optimism were found to be the founding pillars informing these children's creative agency in navigating their schooling experiences. Hence, even though the vulnerable children had challenges in meeting the expectations and values of both their school and home worlds (Cooper, Denner and Lopez 1999), these challenges were surmountable. Instead of dwelling on the negative aspects of these worlds, the findings indicate that the vulnerable children were more focused on how to overcome their challenges than merely lamenting them.

Precious's response "I have no one to help me" is also a strong indication that, even though the vulnerable children used their hidden resilience to work towards their dreams, they could still feel the void of a helper's absence. In concurrence with Ungar et al. (2014), we assert that resilience goes further than a personally resilient behaviour - it also involves the availability of an effective support system that protects these children from further vulnerability by developing their strength and social wellbeing. Therefore, whatever assertive personality the vulnerable child might have to bolster resilience, it has to be supported and nurtured by the society (Ungar 2008). It is lamentable to state that, even if the vulnerable children could strive for their education, without adequate support from external structures such as extended family, school or government to help them, this can become a daunting task. The vulnerable children's active resilience is therefore no guarantee of their educational success and alleviation from unpleasant schooling experiences. The school and community should therefore play their supportive roles to build on these children's agency, resilient personalities and inventiveness in order to help them better adjust to the challenges of their schooling experience and of life in general.

\section{Rebellion against Abusive Teachers}

The study found that rebelling against abusive teachers, who reprimanded and embarrassed the vulnerable children in the presence of other learners, was one of the subversive ways through which these children navigated their schooling experiences. This took the form of a tacit, but carefully orchestrated and calculated behaviour of defiance (for example refusal to take punishment) and opposing school rules and adult 
authority in general. This behaviour ended up fuelling a damaging and denigrating discourse about vulnerable children as ill-disciplined, which placed these children in a vicious cycle and justified further abuse against them. The data below illustrates some ways vulnerable children used to navigate this experience:

We rebel because teachers make us work in the garden as a form of punishment; they then expect us to come to school in clean uniforms the following day. How is that possible?

(Ayanda*, boy aged 11; focus group interview)

Once a teacher tells me that we I am lazy and useless, I start hating that teacher and I do not concentrate but make noise in their classes. The rebuking and embarrassment in front of other learners also make me not respect the teachers.

(Precious*, girl aged 13; focus group interview)

From the findings, we determine that, the vulnerable children used their agency to seek compassion, appreciation and understanding from the teachers. Unfortunately, the teachers in this school provided forms of punishment for delinquent behaviour as illustrated above, which on the contrary aggravated the predicament of the vulnerable children. As the vulnerable children navigated the school spaces, they were confused by the illogical expectations of the teachers. For example, after working in the garden their uniforms were understandably dirty and because of their plight and poverty it was not possible to afford soap to wash on a daily basis, thus wearing a clean uniform the next day was just an irrational expectation for them. Furthermore, instead of being thoughtful of the vulnerable children's plight and supporting their educational endeavours, the teachers perceived them as being "lazy", as expressed by Precious*, which was not only a misjudgement but also literally ignored the extent to which the vulnerable children had worked to rise above their life situations. This misconception did not only leave the vulnerable children with a deep sense of confusion that further exacerbated their vulnerability, but provided a basis for, nurtured and encouraged the development of defiant behaviour in the school (Ungar 2007). From this we learn that teachers should provide the correct social structure through creating caring and sensitive social relationships that nurture and develop socially acceptable resilient behaviours of vulnerable children.

Besides being a survival strategy, the vulnerable children rebelled in order to assert their identity, and become powerful in the school (Ungar 2005). It further served as a defence mechanism and retaliation for the bad treatment they received from their teachers. Being in a defensive mode helped the vulnerable children manage the most controlled school spaces and wield some psychological power that gave them comfort to live with their experience of ill-treatment by teachers.

Rebelling also helps me because it makes me feel like I am in control of my emotions as I give the teachers a taste of their medicine (three of the six vulnerable children in the study nodded their heads in agreement and one clapped hands). 
(Anita*, girl aged 12; focus group interview)

Fortunate* provided this picture to illustrate their defiance in the class (as she took it out, she was delightfully smiling and about three of the other vulnerable children laughed).

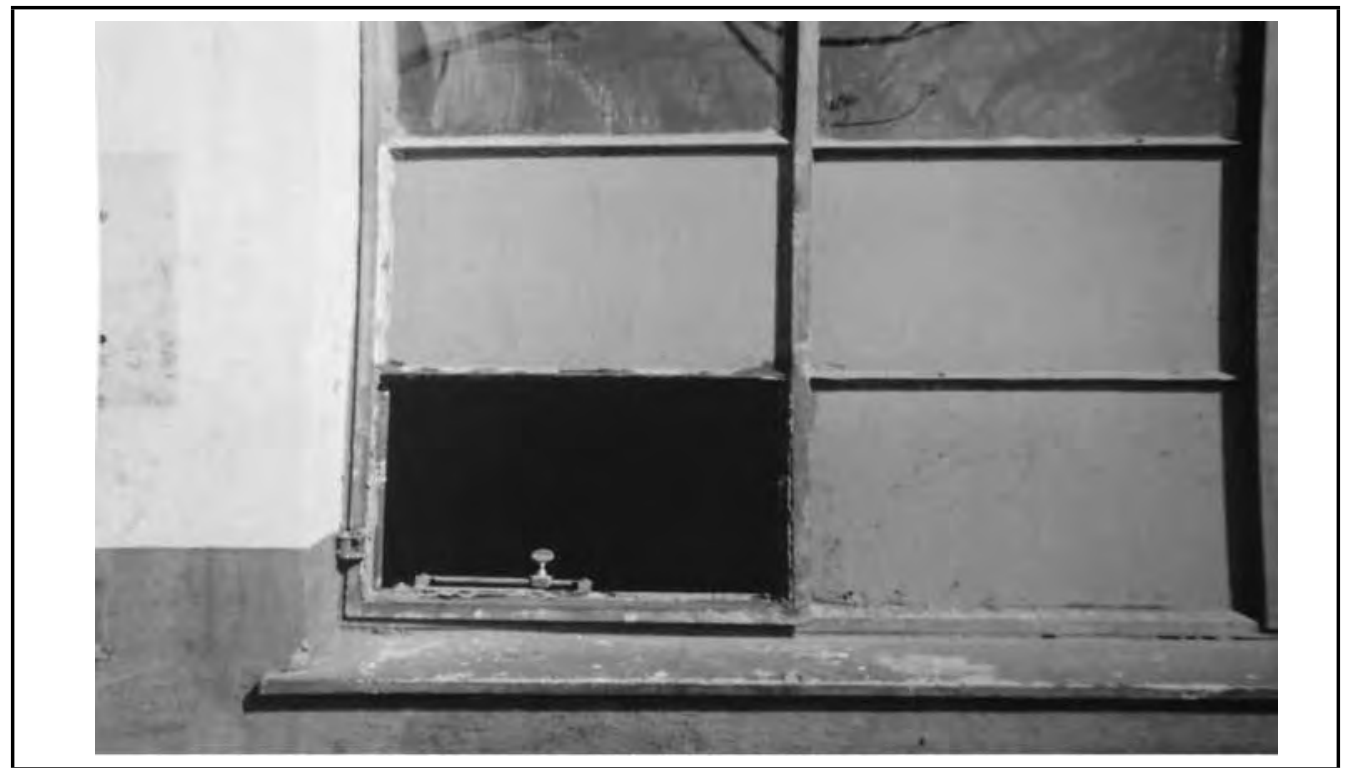

Figure 2: Picture 2

One rainy and cold morning, Miss Kunene (a pseudonym) punished one of my friends who had come late to school. When the teacher came for her lesson, with a few of my friends we made noise. In fact, we were discussing what she had done to the "poor" child and we were not happy about it. The teacher was so infuriated that she threw a duster at us. The duster missed then hit and broke the glass in this window. For a moment, we were all shocked but eventually, we all laughed at how her anger against us embarrassed her.

(Fortunate, girl aged 15; focus group interview)

The data above demonstrates the agency that was employed by vulnerable children in this context to navigate school spaces that oppressed them. Large unruly groups strengthened not only their visibility in the school (Sutton et al. 2007) but also acted as a base from which the vulnerable children could draw their resilience. This denotes a sense of solidarity, amenability and the importance of peer social relationships as a strong base from which the vulnerable children could draw their resilience and thus cope with the negative schooling experiences. The level of wit and adaptability with which these children constructed themselves in the face of a furious teacher is noteworthy. They seemed to have gained a vast experience in dealing with their teacher, and they were able to trigger her weak temper in ways that accorded them moral power as they 
subversively navigated their power relationships with teachers. There is no sense that these children displayed a feeling of powerlessness and helplessness in the face of their abusive teachers. Instead, how they responded to this reveals that when teachers are not responsive and in support of vulnerable children's plight, they (teachers) become the architects of chaos and disorder in their classrooms (Ungar 2005), and thereby compromise the quality of teaching and learning. As exposed by the narratives, it is very difficult for vulnerable children to participate in an educational system in which they are relentlessly dominated and demeaned by adults (Sutton et al. 2007). This is besides the dangers associated with furiously and indiscriminately throwing a duster at children in the classroom.

We learn from this the value of creating a friendly learning environment and peaceful social relationships between teachers and the vulnerable children, where teachers are approachable and encourage dialogue with vulnerable children to communicate their emotions through words rather than actions (Ahn 2010). This would help not only nurture correct resilient behaviours for vulnerable children but also help the vulnerable children to efficiently express their feelings on issues that concern them and thereby make their schooling experiences positive and effective.

\section{Recourse to Isolation and Solitude}

When all other strategies failed and the vulnerable children continued to feel overwhelmed by the challenges related to their home and school environments, they resorted to isolating themselves from other learners. The feeling of having to mingle with the other learners when they were faced with shameful situations in their lives was hard to bear. The data below illustrates:

My uniform no longer fits me well and it shows skin in the armpits and belt line. This makes me not comfortable to be with other learners, thus decide to hide because even though some learners feel bad for us but there are those who make fun of our plight.

(Fortunate*, girl aged 15; individual interview) 


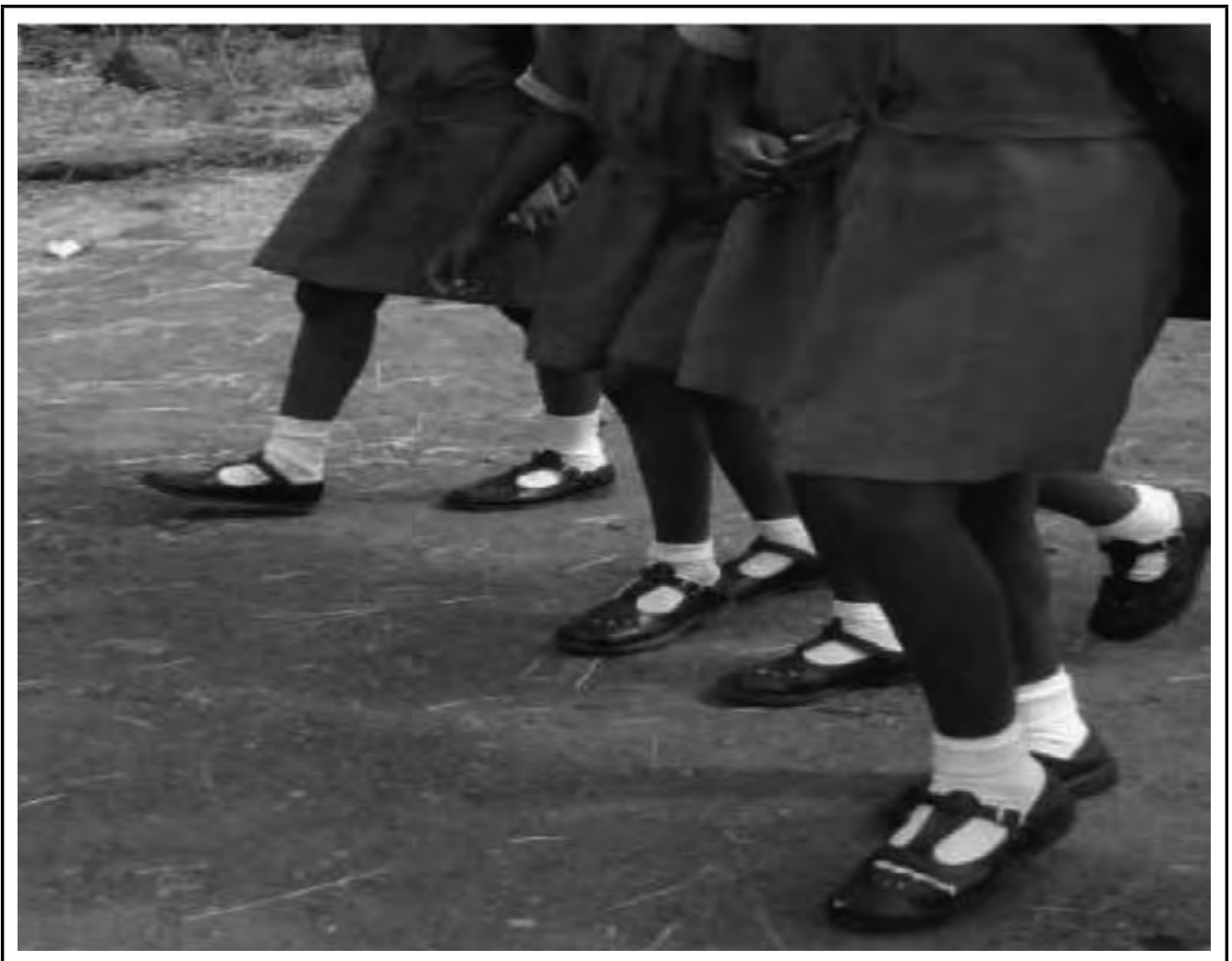

Figure 3: Picture 3

I have been wearing this pair of shoe for two years and now it is torn. When I see a student looking at my feet (shy smile) I feel embarrassed. I enjoy being with my friends, because they do not laugh at me, but other learners do. Unfortunately my friends are in a different class (Grade $6 \mathrm{~B})$, so most of the time, to avoid the scorns and mocking from my classmates, I prefer being alone.

(Precious*, girl aged 13; individual interview)

Gustuff* further provided the photograph below to illustrate how he became emotionally attached to the playground each time he was overcome by his lived experiences, both at home and at the school. The playground gave him a sense of solace and a base from which he could draw his strength to face his daily life challenges. 


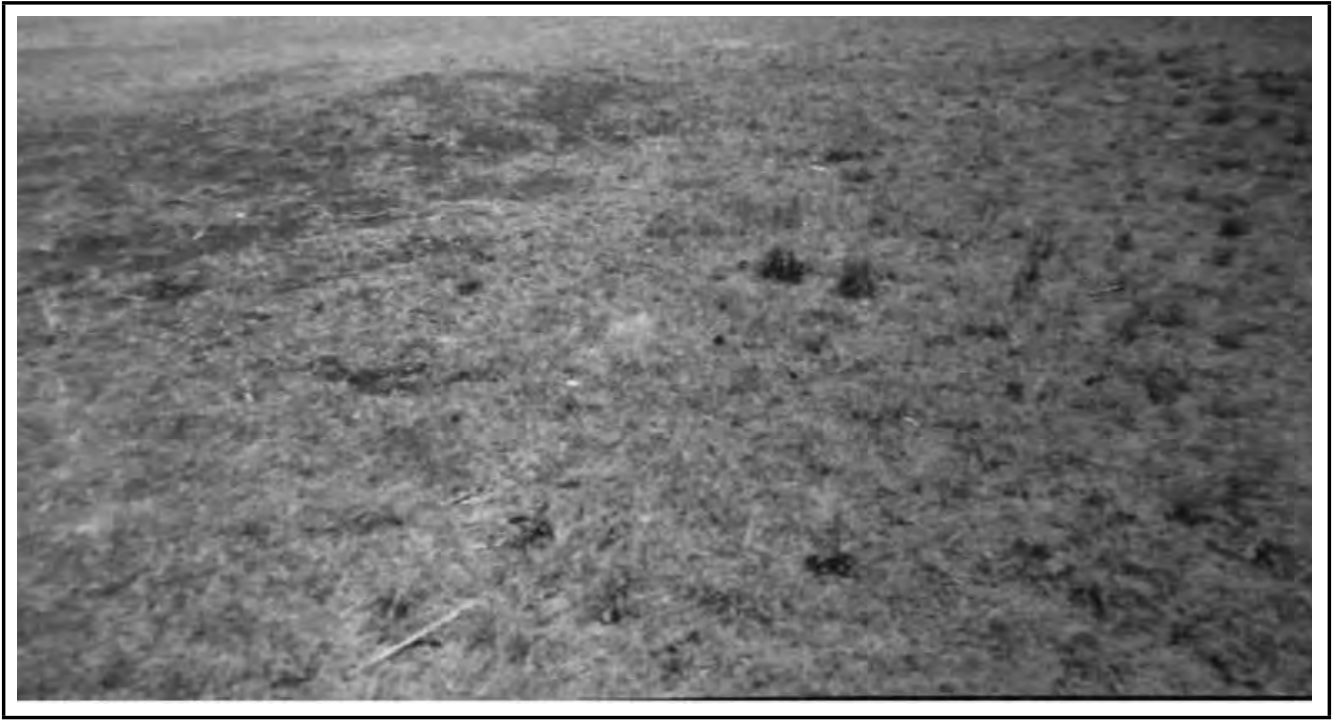

Figure 4: Picture 4

This picture shows the playground. This place is very quiet and conducive for studying. Each time I am here, I forget about the difficulties I face at home or at school and I am able to study [concentrate].

(Gustuff*, boy aged 13; focus group interviews)

Gustuff's picture is a representation of a lonely life of a vulnerable child. It exposes the extent of social exclusion faced not only by the participants of the study, but the daily lived experiences of vulnerable children in the country's schools (Nordtveit 2010). It is a bleak example of the devastating effects of the lack of support systems for vulnerable children in this Southern African region (Lekule 2014), which prompts such children to detach themselves from the school community when the idea of being poor and thus different from other learners has been firmly inculcated (Peace 2001). Gustuff found solace in socially isolating himself, as this was better than the exclusionary and demeaning social relationships of discrimination based on his socioeconomic status. Therefore, a creative resilience option for Gustuff was to execute an emotional attachment to the playground, which afforded him a private space, away from the ridicule and discrimination he experienced at home and the school. This also acted as a space from which he could draw his strength towards resilience and educational success, in the absence of any support.

If vulnerable children, through their hidden resilience, could find solace in isolated and remote spaces from their schooling environments, this is a serious indictment on how uncaring and unsupportive the school system is for these children. From the narratives there is no evidence that the vulnerable children excelled or even did well in their school work, but without social support, a sense of belonging, these children's educational 
resilience is unlikely to be effectively inculcated (Pooley and Cohen 2010). It is clear though, that taking the vulnerable children to school and paying for their educational fees is not enough. There is a need to address teachers' and other learners' attitudes towards vulnerable children and to support them with basic human needs like proper school uniforms, which we argue could go a long way towards mitigating vulnerable children's compromised life circumstances and fostering their resilience (Ungar et al. 2014).

The willpower of these children to learn and adapt themselves in favour of their educational attainment is not at all in question. A reciprocal response from the other stakeholders though was found to be a missing link between the vulnerable children and the quality of their schooling experiences. The actions of the other learners and teachers might not have been intentional. However, these do indicate a need to sensitise teachers, learners and community members about the plight of vulnerable children as individuals and a social group requiring consideration in policy formulation endeavours, and pedagogical and social interactions in and out of school. Only through such support could vulnerable children's individualist resilience abilities be reinforced and harnessed to improve broader structural issues of social transformation, educational inclusivity and their meaningful participation in life (Ungar 2008). This would ensure that the vulnerable children's adverse schooling experiences, as exemplified above, which might compel them to drop out of school, thus entangling them in a vicious cycle of vulnerability and poverty, become alleviated, or at least mitigated.

\section{CONCLUSIONS AND RECOMMENDATIONS}

In traversing the school places and spaces, vulnerable children revealed themselves to be resilient, confident, and very optimistic for a better adult life through education. To bolster their resilience, the vulnerable children drew from social and personal capital as immediately available resources against treacherous schooling spaces. Their agentic prowess was not limited to how they stood in solidarity with other vulnerable children abused by some teachers - they also displayed inventive agency in how they defied the power relationships between teachers and vulnerable learners and continued to see themselves and other vulnerable children in a positive light despite their general denigrating and demeaning schooling experiences. The school on the other hand provided no social support for these children's positive resilient behaviour; on the contrary the teachers provided a basis for rebelliousness as the vulnerable children sought consideration and to assert their identity in the school. Hidden resilience was found to be an overriding coping mechanism used by the vulnerable children to cope amidst the challenges caused by their schooling experiences in the absence of an effective support structure to nurture them in their path to resilience. Through assertiveness and isolation from other learners, the vulnerable children demonstrated competency as sound, reasonable, and intelligently adaptive human beings. 
To help build on the creative ways vulnerable children used to navigate their schooling experience, the study recommends:

- Schools should infuse resilience affirmation and self-efficacy as a cross-cutting component of the school curriculum, and teachers could implement this in their pedagogical and social interactions with vulnerable children.

- There is a need to foreground vulnerable children's ingenuity as a foundation for strategies and reforms aimed at improving the quality of their schooling experiences.

- The creation of a friendly environment of care and support for improved teacherlearner and learner-learner relationships, with strong emphasis on social diversity tolerance and acceptance enhancement.

The above recommendations could further be enhanced through the alleviation of patriarchy and the creation of democratic civil organisations in Swaziland. These would cultivate a platform for conducive and democratic schooling environments, which accentuate the importance of foregrounding sensitive, thoughtful and caring social relationships from all educational stakeholders in the development and nurturing of resilience and self-efficacy in vulnerable children. This could be possible through concentrating not only on the teaching and learning aspect, but also the emotional wellbeing of the child. Equally important is the implementation of pedagogical practices that would foster a sense of belonging for the vulnerable children. Other learners in school contexts need to be sensitised regarding the importance of an equitable school environment where vulnerable children are equitably affirmed, not discriminated against.

\section{Limitations of the Study and Implications for Further Research}

Although the use of six participants provided valuable qualitative insights, the findings of this study cannot be generalised beyond these six participants and the time and space within the context of the school in which the study was conducted. Further qualitative research using a larger sample of participants, over a long period, within a variety of school contexts in this region, is needed to provide further insights into dynamics of resilience for vulnerable children within the schooling contexts of Swaziland. Notwithstanding, this current study serves a pioneering role providing information to sensitive researchers in the country about the plight of vulnerable children, and the need to conduct research that foregrounds their voices regarding the kind of support they need to augment their overall resilience in order to overcome challenges related to their schooling.

\section{REFERENCES}

Ahn, J. 2010. “'I'm Not Scared of Anything': Emotion as Social Power in Children's Worlds.” Childhood 17 (1): 94-112. 
Braithwaite, J., L. S. Djimba, and R. Pickmans. 2013. Child and Orphan Poverty in Swaziland. University of Virginia: UNICEF.

Braun, V., and V. Clarke. 2006. "Using Thematic Analysis in Psychology." Qualitative Research in Psychology 3 (2): 77-101.

Cooper, C., J. Denner, and E. Lopez. 1999. "Cultural Brokers: Helping Latino Children on Pathways toward Success." The Future of Children 9 (2): 51-7.

Di Cicco-Bloom, B., and B. Crabtree. 2006. "The Qualitative Research Interview." Medical Education 40 (4): 314-21.

Gallacher, L., and M. Gallagher. 2008. "Methodological Immaturity in Childhood Research? Thinking through 'Participatory Methods'.” Childhood 15 (4): 499-516.

Garutsa, T. C. 2012. "The Role of Non-Governmental Organisations in Addressing the Needs of Orphans and Vulnerable Children in Marondera District, Zimbabwe." Master's dissertation, University of Fort Hare. http://citeseerx.ist.psu.edu/viewdoc/download?doi=10.1.1.465.3460\&rep=rep1\&type=pdf (accessed December 1, 2014).

Gee, J. P. 2011. An Introduction to Discourse Analysis: Theory and Methods. 3rd ed. New York: Routledge. Gergen, K. J. 2009. An Invitation to Social Constructionism. London: Sage.

Glover, J. 2009. Bouncing Back: How Can Resilience Be Promoted in Vulnerable Children and Young People? Ilford: Bernados.

Jans, M. 2004. "Children as Citizens: Towards a Contemporary Notion of Child Participation." Childhood 11 (1): $27-44$.

Joubert, I. 2012. "Children as Photographers: Life Experiences and the Right To Be Listened To." South African Journal of Education 32 (4): 449-64.

Khumalo, T. 2013. Swaziland: Effective Delivery of Public Education Services. Johannesburg: Open Society Initiative for Southern Africa.

Kingdom of Swaziland. 2010. National Plan of Action for Children (NPA) 2011-2015. http:// washinschoolsmapping.com/wengine/wp-content/uploads/2015/10/Swaziland-National-Plan-ofAction-for-Children.pdf (accessed December 17, 2014).

Kingdom of Swaziland. 2013. "Swaziland Schools' Lists, 2013." Ministry of Education and Training circular. Mbabane, Swaziland: Government Printer.

Lekule, S. 2014. "Investigating School Experiences of Vulnerable Children in Singida, Tanzania. Challenges, Strategies, and Possible Interventions." PhD dissertation, University Of Windsor. http:// scholar.uwindsor.ca/cgi/viewcontent.cgi?article $=6081 \&$ context $=$ etd (accessed October 15, 2015).

Malindi, M. J. 2014. "Exploring the Root of Resilience among Female Street Involved Children in South Africa." Journal of Psychology 5 (1): 35-45.

Malindi, M. J., and L. C. Theron. 2010. "The Hidden Resilience of Street Youth." South African Journal of Psychology 40 (3): 318-26.

Mcmillan, J. H., and S. Schumacher. 2010. Research in Education. Evidence-Based Inquiry. 7th ed. New Jersey: Pearson.

Mitchell, C., R. Moletsane, J. Stuart, T. Buthelezi, and N. de Lange. 2005. "Taking Pictures/ Taking Action! Visual Methodologies in Working with Young People." Children First 9 (60): 27-30.

Naysmith, S., A. Whiteside, and A. Whalley. 2008. "Rethinking Swaziland's HIV/AIDS Epidemic: The Need for Urgent Interventions." Canadian Journal of Public Health 99 (1): 58-9.

Noltemeyer, A., and K. R. Bush. 2013. "Adversity and Resilience. A Synthesis of International Research." School Psychology International 34 (5): 474-87.

Nordtveit, B. 2010. "Schools as Agencies of Protection in Namibia and Swaziland: Can They Prevent Dropout and Child Labour in the Contexts of HIV/AIDS and Poverty?" Comparative Education Review 54 (2): 223-42.

Nyabanyaba, T. 2009. Factors Influencing Access and Retention in Secondary Schooling for Orphaned and Vulnerable Children and Young People. Case Studies from High HIV and AIDS Prevalent Contexts in Lesotho. London: University of London. 
Peace, R. 2001. "Social Exclusion: A Concept in Need of Definition.” Social Policy Journal of New Zealand 16: $17-36$.

Pooley, J. A., and L. Cohen. 2010. "Resilience: A Definition in Context." The Australian Community Psychologist 22 (1): 30-7.

Simelane, M. 2016. "OVC Crisis as Applicants Double." The Times of Swaziland, January 28, 2-3.

Sukati, C. W. S. 2013. "Education for All Children by 2015: Mere Rhetoric or Reality in Swaziland?" International Journal of Education and Research 1 (11): 1-12.

Sutton, L., N. Smith, C. Dearden, and S. Middleton. 2007. Child's Eye View of Social Difference. New York: Joseph Rowntree Foundation.

Swaziland. 2012. Swaziland Economic Outlook. www.africaeconomicoutlook.org (accessed February 17, 2016).

The Swaziland Ministry of Education and Training. 2011. The Swaziland Education and Training Sector Policy. Mbabane: Government Printer. http://planipolis.iiep.unesco.org/upload/ SwazilandEducationSectorPolicy2011pdf (accessed October 19, 2015).

Theron, L. C. 2012. "Resilience Research with South African Youth: Caveats and Ethical Complexities." South African Journal of Psychology 42 (3): 333-45.

Ungar, M. 2005. "Delinquent or Simply Resilient. How 'Problem' Behaviour Can Be a Child's Hidden Path to Resilience." Voices for Children, 1-10. http://lwww.resilienceresearch.org/files/PDF/ Delinquent\%20or\%20simple\%20resilient.pdf (accessed December 4, 2016).

Ungar, M. 2007. "The Beginnings of Resilience. A View across Cultures." Education Canada-Toronto 47 (3): $28-38$.

Ungar, M. 2008. "Resilience across Cultures.” British Journal of Social Work 38 (2): 218-35.

Ungar, M., P. Russell, and G. Connelly. 2014. "School-Based Interventions to Enhance the Resilience of Students." Journal of Educational and Developmental Psychology 4 (1): 66-83.

UNICEF. 2009. Promoting Quality Education for Orphans and Vulnerable Children. A Source Book of Programme Experiences in Eastern and Southern Africa. New York: UNICEF. http://www.unicef. org/spanish/education/files/Promoting_Quality_Education_for_Orphans_and_Vulnerable_Children_ Programmes_from_Eastern_and_Southern_Africa.pdf (accessed August 22, 2016).

United Nations Development Programme (UNDP). 2012. "National Human Development Report Concept Paper, Governance and Inclusive Growth." Mbabane, Swaziland.

United Nations Development Programme (UNDP). 2016. "Human Development Report 2016. Human Development for Everyone.” Briefing Note For Countries on the 2016 Human Development Report. Swaziland. http://hdr.undp.org/en/countries.Swaziland (accessed August 22, 2016).

Van Blerk, L. 2005. "Negotiating Spatial Identities: Mobile Perspectives on the Street Life in Uganda." Children Geographies 3 (1): 5-21.

Voyk, E. 2011. "Orphan and Vulnerability, NGOs and HIV/AIDS in Ghana." Honours dissertation, The Ohio State University. http://hdl.handle.net/1811/48951 (accessed December 1, 2014).

Wang, C. 1999. "Photovoice: A Participatory Action Research Strategy Applied to Women's Health." Journal of Women's Health 8 (2): 185-92. 